\title{
ESCRITURA HABLADA: EL LIENZO DE LA ALTERIDAD, DIÁLOGOS DE CIUDADANÍA
}

\section{SPOKEN WRITING: VOICES OF OTHERNESS, CITIZENSHIP DIALOGUES}

\author{
MARÍA VICTORIA MARTÍNEZ-VÉREZ*
}

Resumen: Con el objetivo de conocer las facetas cognitiva, simbólica y emocional que conlleva todo proceso comunicativo, en 2017 un equipo del Centro de Formación Profesional Ánxel Casal (Coruña, España) realizó un proyecto de arte de acción, que tuvo como resultado relatos de ciudadanos que se mantuvieron a la escucha en tanto interlocutores productivos. Este artículo da cuenta de esa experiencia y del análisis de los relatos resultantes.

Palabras Clave: Comunicación, alteridad, lenguaje emocional, arte de acción, ciudadanía.

Abstract: With the aim of exploring the cognitive, symbolic and emotional dimensions implicit in any communicative process, a team from the Centro de Formación Ánxel Casal (Coruña, Spain) began an action art project in 2017, which produced testimonies from citizens who listened in as productive interlocutors. This article gives an account of this experience and analyzes the resulting testimonies.

KEYwORDs: Communication, otherness, emotional language, action art, citizenship.

Recibido: 09.04.2018. Aceptado: 06.09.2019

\section{INTRODUCCIÓN}

"Toda cosmología es una cosmología hablada” Bachelard (1982)

T A VOZ DE LA CIUDAD se cuela en el paisaje marítimo, dando vida a diáLlogos imposibles fuera del ámbito de la expresión humana, diálogos

* Doctora en sociología. Académica del Centro Integrado de Formación Profesional Ánxel Casal (CIFP) y de la Universidad Nacional de Educación a Distancia (UNED), La Coruña, España. Correo electrónico: vita.martinez.verez@gmail.com. Orcid: https://orcid.org/0000-0002-8417-510. 
que son precisamente el germen sociológico del concepto de ciudadanía, entendido como lazo o ligazón emocional que se relaciona en el Nos-otros, y que se define en oposición al Ellos (Bauman, 2007). Las personas son ciudadanas de un paisaje vivo que conforma identidades y pertenencias; el lugar que habitamos construye las palabras que nos decimos y evoca olores, tactos, sabores, imágenes y sonidos que tienen sentido en el "aquí y ahora", en las coordenadas precisas que habitamos y que nos habitan (Sánchez, Chacón y Belda, 2011), existiendo un paisaje interior de referencia que, a su vez, nos permite imaginar pre-conceptualmente otros desconocidos, y que es común entre quienes comparten una comunidad.

Una de las fronteras de la realidad percibida es el lenguaje, ya que la acción de decir el mundo social es, a la vez, límite, porque nada existe fuera del verbo, y punto de encuentro interpersonal. Para que la expresión cobre sentido holístico es necesario ponerse de acuerdo en las palabras que nos decimos, y estas son propias del lugar y de las personas que lo habitan.

El sonido de la voz, la concordancia, la declinación de las formas verbales, la cadencia fonética y hasta el timbre sonoro, son matices de luz que dibujan el paisaje interior del cuerpo social. Así, nuestra lengua es pluma de gaviota o de colibrí, cuerpo de mar o de río, piel de costa o de interior, camino de cauce o de estepa, arena de playa o de desierto, voz de luna o agua de sol; infinitas variables construyen el mundo que habitamos y que nos habita por dentro.

En este sentido, ser ciudadano o ciudadana es más que el libre ejercicio de unos derechos inalienables, implica sentirse parte del territorio, de su idioma, de su acento, de su luz, de su clima, de los seres que lo anidan. Implica habitarlo desde dentro, sabiéndose parte constructora del mismo; para ello, hay que sentir "en el yo" y compartir "en el otros" una vivencia que permita resignificar el lugar en torno a la propia piel, de modo tal que podamos identificar nuestras propias contribuciones al hecho social de habitarlo. Cualquier persona puede saberse la orografía de su territorio, pero solo los ciudadanos pueden amarlo y respetar el consenso social y humano que teje la tierra al cuerpo en formas temporales y topográficas.

\section{LOS APRENDIZAJES TRANSVERSALES EN EL SISTEMA EDUCATIVO ESPAÑOL}

El ejercicio de los derechos de ciudadanía forma parte de los aprendizajes vinculados a la inteligencia emocional, presentes en las leyes de educación españolas, los cuales permiten, al alumnado, adquirir un conjunto 
de destrezas sociales que favorecen los procesos grupales de integración, la solución de conflictos y la expresión controlada de las emociones. Pero, al ser estas habilidades abordadas de un modo cognitivo, la vivencia de las emociones y los sentires, queda relegada a los márgenes (objetivos) del modelo de educación tecnócrata, que en la actualidad se ha impuesto en los centros de enseñanza (Ortega, 2013); sin tener en cuenta que solo aquello que se vivencia a través del roce con el cuerpo sensible del otro (subjetivo), puede aprenderse y permanecer como habitante callado de la memoria que nos construye en lo humano. Somos hijos de la experiencia continua que tejemos con las distintas otredades para construir el cuerpo social sobre la base del consenso y la creencia.

Tras comprobar la ineficacia de esta metodología de corte tecnocrático que privilegia los procesos cognitivos y procedimentales, y relega las formas subjetivas y sensibles de acercarse al conocimiento humano, Moreno (2015) propone el empleo de la expresión artística como herramienta mediadora para trabajar las habilidades que conforman los procesos sociales (Giráldez y Prince, 2017). Ya que, para que el encuentro entre emoción, símbolo y cognición se produzca en toda su potencialidad, es necesario emplear un nexo entre las personas y sus experiencias vitales. Ahondando en esta visión, Tejo (2017) propone el arte de acción como instrumento para trabajar las emociones que subyacen en nuestras conductas, con el fin de lograr que estas sean lo más adaptativas posibles; aplicando, de este modo, las destrezas sociales relacionadas con la inteligencia emocional, a la vida en relación, en lugar de solo memorizarlas (Terrones, 2013).

El arte de acción es una práctica efímera, en tanto que no pretende perdurar en el tiempo, sino más bien dar sentido al tiempo; y performativa en cuanto a la capacidad de vincular a las personas con un significado nacido de la vivencia compartida de un espacio (Segura-Cabañero y Simó-Mulet, 2017).

Además, su marcado carácter procesual, por un lado, privilegia la significación de las acciones (tanto individuales como colectivas) por encima del resultado final y, por otro, permite que los relatos individuales de los participantes (proponentes o receptores) convivan con otros más amplios, generando micro narraciones en lugar de una sola narración (Zaliasnik, 2017).

Su necesario carácter colectivo y participativo constituye en sí mismo una metodología de aprendizaje horizontal, generando conocimiento experiencial, en lugar de verticalidad y transmisión conceptual. Esta característica es fundamental en los aprendizajes relacionados con "el saber ser y estar en el mundo", propios de la inteligencia emocional. 


\section{PROPUESTA PEDAGÓGICA}

De acuerdo con las apreciaciones señaladas en el apartado anterior, desde el año 2008 se viene trabajando de acuerdo con una propuesta pedagógica, que es continuamente revisada, tanto interna como externamente, (proceso de investigación- acción - participación, Macaya, 2017), a través de la evaluación de pares externos y la consiguiente publicación en revistas indizadas en bases de datos académicas, WOS, Scopus y Latindex, así como mediante la participación de la autora, en proyectos de innovación pedagógica, (convocatorias ministeriales años 2014 y 2017), centrados en el desarrollo de las competencias "aprender a aprender"; "habilidad de trabajo en equipo" y en "la construcción de contenidos audiovisuales accesibles a la docencia”. Esta propuesta pedagógica está dividida en dos bloques interrelacionados; el cognitivo que aborda los grandes conceptos definidos en el currículum, y el práctico que abarca el 70\% de las horas docentes, y que consiste en un proyecto de arte de acción, que se articula de acuerdo con los rasgos que, según Zaragoza; Luis-Pascual y Manrique (2009), comparten las estrategias innovadoras, a saber: parte de una propuesta didáctica no directiva, que utiliza la expresión artística como instrumento mediador; se desarrolla en el campo social; en el momento presente; con los/as compañeros/as; improvisando las circunstancias surgidas en el día a día; incluyendo a la ciudadanía como co-protagonista del proceso artístico, amplificando de este modo la resonancia de la acción; valora el desarrollo del proceso, e incorpora el lenguaje emocional como variable esencial de todas las acciones.

Atendiendo a este proyecto docente, en el curso 2016-2017, se solicita al alumnado del CIFP Ánxel Casal, centro de referencia regional para la familia de servicios a la comunidad, escribir diariamente, durante los meses de enero a marzo, un emocionario a gran escala, ocupando por entero el cercano arenal de Las Lapas, próximo a la Torre de Hércules, antiguo faro romano, reconocido en el año 2009 como Patrimonio de la Humanidad. En este tiempo dibujaron 45 mensajes con algas, dirigidos a un interlocutor invisible, la ciudadanía. La premisa que da vida a la acción es la siguiente: La comunicación es un proceso que nace entre líneas, la de la voz y la del silencio, siendo ambas pautas necesarias para dar forma al renglón del diálogo y del entendimiento (Gueyrand, 2015).

El proceso de escritura se iniciaba cada mañana en el aula, eligiendo por consenso los mensajes que se querían transmitir. Posteriormente, la totalidad del grupo caminaba hasta la playa, donde se distribuían las tareas, 
de tal modo que, mientras unos buscaban algas para marcar las letras, otros escribían con los pies en la arena los mensajes. Al terminar, se fotografiaba y celebraba el texto en las inmediaciones de la playa, para regresar al aula, y realizar un seguimiento del eco que tenía la escritura en la ciudadanía, bien a través de las redes sociales, o del intercambio verbal y escrito.

Es importante señalar que la acción descrita anteriormente no constituye una experiencia artística aislada, de tipo celebrativo, que se describe, atendiendo a su originalidad, sino que forma parte de una estrategia pedagógica, analizada y revisada, que utiliza la potencialidad del arte de acción como herramienta mediadora en la adquisición de las habilidades propias de la inteligencia emocional y que, como tal, ha de entenderse y escucharse.

\section{PARTICIPANTES}

En el desarrollo del proyecto participaron dos grupos, uno de ellos formado por 51 estudiantes de los ciclos de formación profesional de servicios a la comunidad (6 hombres y 45 mujeres), que actuaron como emisores; el otro grupo, de número no precisado, participó como observador involuntario del proceso y primer receptor del mensaje. La prensa local y las redes sociales (twitter, instagram y whatsapp), actuaron como eco sonoro del proceso comunicativo, facilitando la visibilidad de la acción. Asimismo, una profesora del área de artes y humanidades coordinó el desarrollo del proyecto, participando "in situ".

\section{ANÁLISIS DE LA PROPUESTA PEDAGÓGICA}

En toda acción comunicativa, las dos voces de Aleixandre (1932), "háblame, te escucho" interactúan tejiendo los microrelatos de los participantes en una narración colectiva.

Con el fin de conocer los significados simbólicos y emocionales que nutren la intervención artística desde la perspectiva del oyente, la investigadora realizó una observación sistemática de los discursos de las personas receptoras, atendiendo a cuatro dimensiones, las cuáles permitieron profundizar en el objeto de estudio: 1) La interacción entre la ciudadanía y la acción artística propuesta; 2) la relación entre las circunstancias interpersonales y la interpretación de los mensajes; 3 ) la (no) neutralidad de los espacios comunitarios; y 4) la aportación del arte de acción como herra- 
mienta mediadora en los aprendizajes transversales que necesiten vivencia además de cognición.

Para alcanzar el grado de saturación y riqueza necesario para conseguir el objeto de estudio, las personas observadoras fueron seleccionadas atendiendo a tres criterios (Ruiz Olabuénaga, 2012): 1) Realizar una observación continuada y demostrada en el tiempo; 2) desconocer la finalidad de la acción; y 3) sentirse interpelados por los mensajes desde alguna de las perspectivas de la comunicación: significativa, simbólica y emocional.

De acuerdo con esta triple pauta, se eligió a la proponente y a tres interlocutores - destinatarios ( 2 mujeres y 1 hombre). El primer interlocutor, debido a las exigencias de su empleo, asistió "in situ" a la fase diaria de escritura, por lo que su rutina se vio asaltada por la intervención, alterando su trabajo; la segunda fue protagonista de un mensaje concreto, dirigido a acompañar su enfermedad y hospitalización, que le sirvió para simbolizar ambos procesos; la tercera interlocutora realizó un seguimiento exhaustivo de la acción, volcando la información a través de facebook, prestando sobre todo atención a los mensajes de índole emocional.

Se solicitó tanto a la proponente como a los tres participantes continuar con su colaboración; para ello se les pidió que detallaran sus opiniones, emociones y expectativas respecto al proyecto. A continuación, la investigadora reformuló los relatos recogidos, generando un intercambio comunicativo, que concluyó cuando los participantes consideraron que condensaban la totalidad de la vivencia. Para ello, se empleó una adaptación de los estudios cualitativos de panel (Sun Woong, 2008), denominada "de cohorte" (De Keulenaer, 2008), que está pensada para el análisis a nivel individual de quienes hayan experimentado un determinado evento; en esta ocasión, los receptores del proyecto de arte de acción. Una vez completado este proceso de reformulación, la investigadora clasificó los relatos atendiendo a las tres perspectivas de la comunicación, y los analizó, de acuerdo con la propuesta fenomenológica de Vidal Jiménez (2006), la cual justifica el empleo de formas no convencionales para conocer aspectos relacionados con la subjetividad e intuición, permitiendo de este modo penetrar profundamente en las narraciones personales que explican una vivencia (MartínezVérez, Abad-Molina y Hernández-Pinzón, 2017).

En este sentido, parece importante indicar, que, en las disciplinas artísticas y humanas, la investigación académica penetra en el mundo subjetivo del sujeto, ya que una de sus finalidades es reconocer la significación del acto cultural, la cual emerge del vaivén incesante entre realidad social e intersubjetividad humana (Winnicott, 1971). 
En el siguiente apartado, se recogen los relatos que, desde una perspectiva personal y poética, narran la experiencia sensible de los receptores, atendiendo a las dimensiones del estudio.

\section{VOCES DE ALTERIDAD EN EL LIENZO DEL OCÉANO}

\subsection{La firma del mar}

Todo acto comunicativo nace de la necesidad de expresar algo por parte de alguien. Es inevitable decir aquello que llevamos dentro, a nadie en concreto, y a alguien, si escucha (Watzlawich, Beavin y Jackson, 2002). Así, este primer relato narra en primera persona el deseo de la proponente, su origen, los versos que brotan del camino de sus pies.

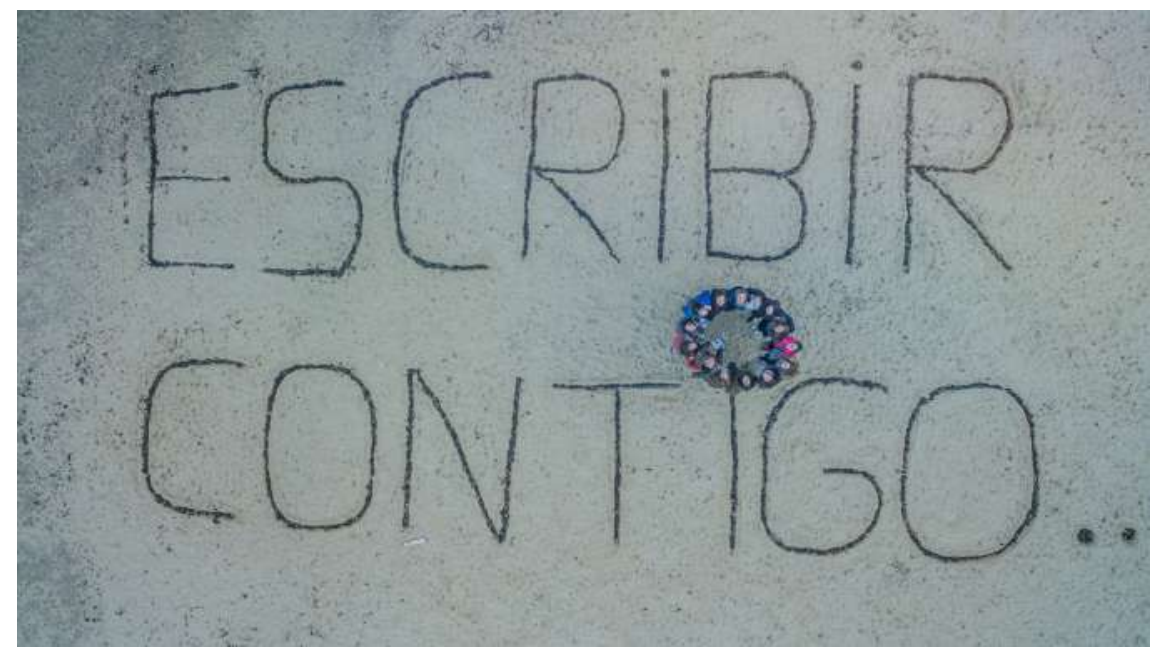

Figura 1. Escribir contigo. CIFP Ánxel Casal (enero de 2017). Foto de David Varela Ramos y Vita Martínez-Vérez.

La voz del océano en la caracola

Mi voz es un relato escrito por mis padres, en la penumbra de una habitación una mañana de invierno.

Tal vez lloviese o no.

Hilos de agua... 
No lo sé.

Mientras se hablaban la piel, el océano estaba presente, escribiendo en la arena, lienzo infinito de sí, su propio sonido. Así fue como nací a la luz. Sin más.

Soy amura de sal. Algas. Caligrafía de viento...

Crecí frente al mar, en la costa de un mundo que se acaba y empieza ahí mismo.

La arena, las olas, los senderos, hablan de mí, conmigo, para mí. Con ellos soy lienzo finito, conversación, cuerpo de escritura. Un times new roman de formato libre.

Nada... Todo...

Desde la orilla, observo a las personas (ad)-mirar el horizonte que dibuja el océano.

A menudo pienso en la pauta Montessori del mar, interpretando continuamente la frontera precisa de la costa, en esa alteridad que acota nuestra jerarquía de infinito.

${ }_{-}^{-}$Hasta aquí, yo $i$ - gritan las olas.

-Nadie contesta...

El arenal forma parte de mi geografía cotidiana, de la soledad que me acompaña, de la voz del grillo.

Su piel es un folio en blanco que pide a gritos ser escrito, leído, acotado.

(...)

Cada día amanezco junto al mar en mil tonos de grises.

Clave de lluvia.

Bajo a la playa, y los pies comienzan a hablar, estableciendo un diálogo con un interlocutor indefinido. Tú, por ejemplo, que escuchas y dices.

Son voz, eco y resonancia.

Pausa...

En una especie de rutina de lo inesperado, hundo a fondo el pie en la arena, y lleno las letras de algas.

Mientras el océano se adormece en la bajamar, Tú, al otro lado del margen, lees los trazos inconexos de las palabras deslizantes y trazas tu propia melodía.

Cada noche, la marea prepara el lienzo y recarga la tinta de palabras. Cada noche es una nueva posibilidad, un comienzo y un final.

Somos a la vez, texto, lectura, grafía y lápiz.

Gracias.

\subsection{La resonancia: el devenir de la costa}

Los siguientes relatos recogen la resonancia del proceso comunicativo, son la voz de quienes escuchan y se sienten interpelados por las letras, incorporando la voz de la acción artística a su narración personal. Cada relato 
expresa o acentúa un aspecto de la interacción, cognitivo, simbólico y/o emocional.

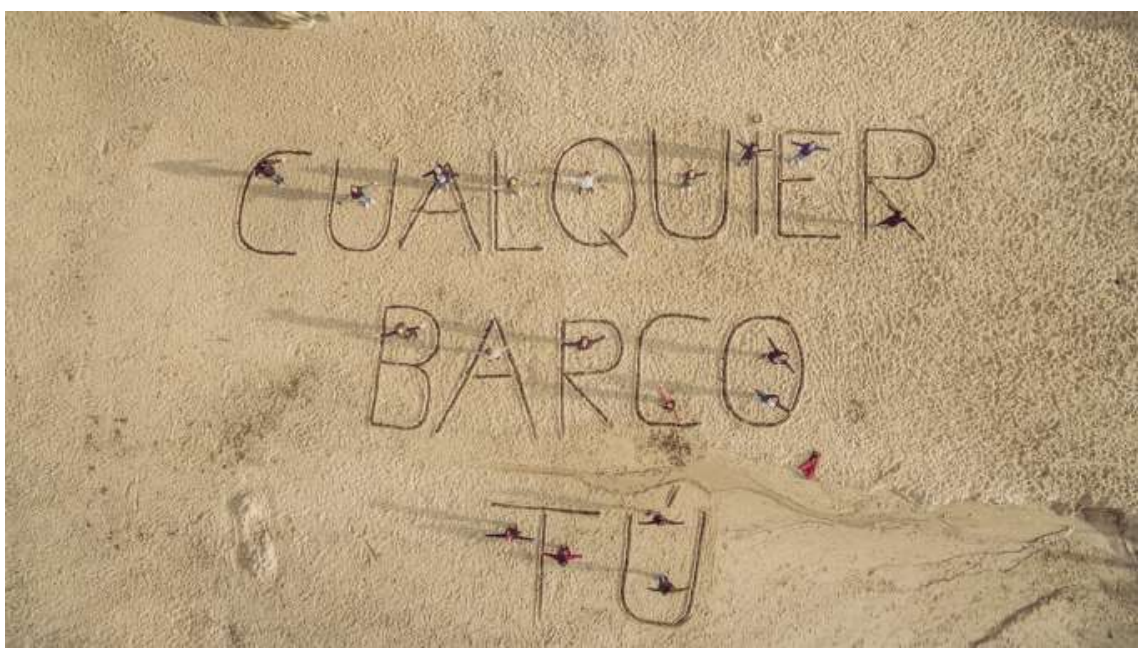

Figura 2. Cualquier Barco, Tú. CIFP Ánxel Casal (febrero de 2017). Foto de David Varela Ramos y Vita Martínez-Vérez.

Tú cuidas mi jardín

Era todos los días. Bajaban juntos, riéndose, cobijándose de la lluvia, del frío, del viento. A veces pensaba, hoy no. Hoy no puede ser posible. Pero justo entonces el sendero se llenaba de voces y aparecían. Ella me sonreía. Yo también. No hablábamos.

En la playa se movían silenciosos, cada uno ejecutaba su tarea con concentración absoluta, como si les fuera la vida en ello, como si les fuera la vida... ¿Por qué?

Desde lo alto, mis manos cortan la hierba, contemplando.

Un día le pregunté: dime ¿Por qué? Sus labios callaron quietos en una curva, se mordió el labio inferior, como buscando una palabra. Entonces dijo, por qué no. Y comprendí.

A la mañana siguiente, al pasar, sonrió, y supe que iban a escribirme. No pasaban los minutos.

A veces, desde el campo de la Torre, la sorprendía buscándome con la vista. Ella me miraba. Comprobando mi atención. Poco a poco la arena fue dibujando las letras. “Tú cuidas mi jardín”. No sé bien que sentí.

Regresaban. Al verme esperando, me dijo: es un gracias, a ti, que me acompañas con tu voz cada mañana, haciendo de mi cuerpo la tierra 
que tú cavas. Y se marchó. Siguieron bajando día tras día. Fui testigo de su despedida. La espiral de cuerpos. La firma del Mar. El aula imposible. Y creí en cada palabra. Fui texto y voz suya. Increíble.

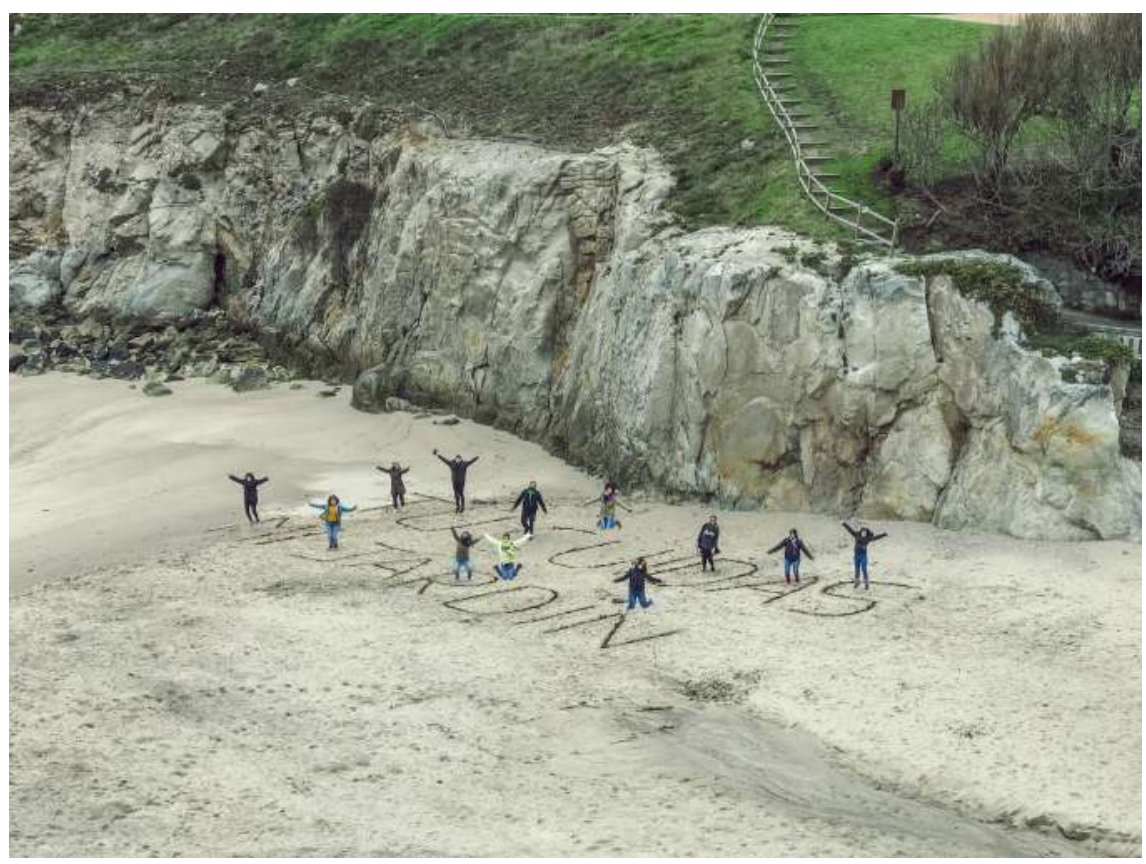

Figura 3. Tú cuidas mi jardín. CIFP Ánxel Casal (marzo de 2017). Foto de David Varela Ramos y Vita Martínez-Vérez.

Vivir-te

Mi cuerpo lleno de enfermedad se dolía en la incerteza. Lo peor es no conocer el mañana. Recuerdo las primeras pruebas, el diagnóstico, los cuidados, el dolor físico. Todo.

Al inicio de ese proceso, Él estaba. Me miraba escuchando el interior. De cerca. De lejos. Recaía. Ingresaba. Salía. Y Él estaba. Estaba en esa permanencia que apenas se puede entender desde la lógica abstracta. Se fue a otra ciudad, pero estaba.

Una mañana la sangre delató de nuevo la presencia de la enfermedad. Se lo dije. Casi sin palabras. Un nuevo ingreso. Más incertidumbre. ¿Merecía la pena? No.

En el hospital, el teléfono sonaba, pitidos sordos reclaman mensajes, abrí uno de ellos. 
Lloré.

Lloré.

Lloré.

Lloré de vida.

Ahí estaba él con otros, escribiendo en la playa un mensaje: "Vivirte, Aloia". "Vivir-te"

Fue tal el impacto de las letras, la emoción, el encuentro, que, una vez superado el desenlace, me tatué el mensaje en el brazo. Me recuerda lo inesperado de los días. La belleza. Cada posibilidad. No me rendiré nunca. Ni él tampoco. Ni ella. Ni ellos. No sabría...
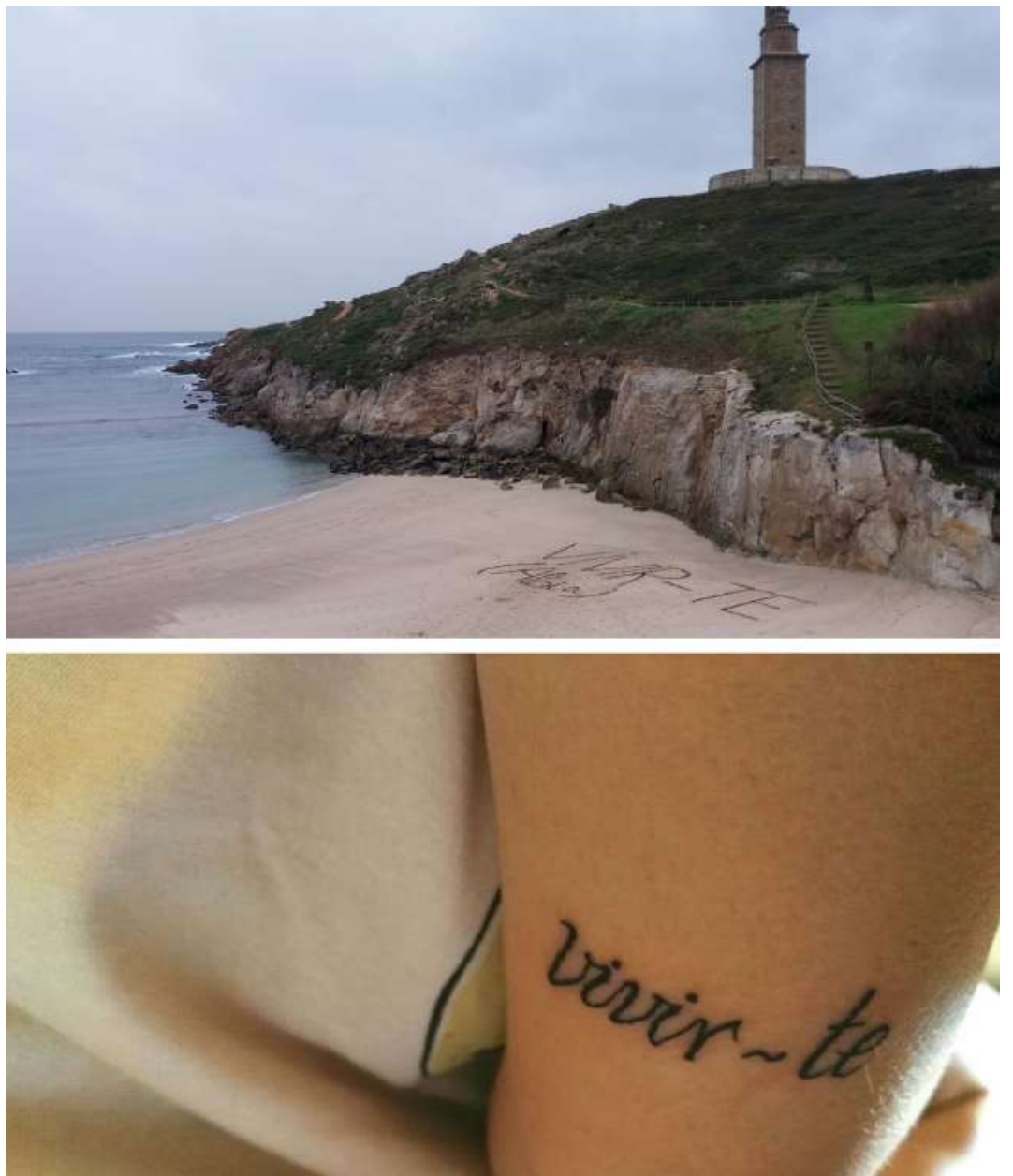

Figura 4. Vivir-te Aloia. CIFP Ánxel Casal (febrero de 2017). Foto de David Varela Ramos y Vita Martínez Vérez. 


\section{Empápate de locura}

Cada mañana salía a pasear, suelo hacerlo, es parte de mi rutina, una más entre otras. Caminaba rápido, costeando, como un barco o una gaviota. Entonces, leí en la playa, escrito con unas letras enormes: Te miro, sin verte. No había nadie. Era como si me esperara. Lo fotografié. ¿Será para mí? ¿Quién lo habrá escrito? ¿Él...? Miles de preguntas.

A la mañana siguiente, salí rápido de casa. Sería mucha casualidad encontrar otro mensaje, mucha. Ahí estaba: El amor se hace.

Mis amigos dicen que "tal vez yo tenga alma de sirena." Sí. Es posible. Y me sugieren que le deje un comentario, algo así como un post. Pienso en hacerlo, pero no me atrevo. Es mejor así, seguir jugando con el misterio, sintiéndome parte. Prefiero.

Entre mis amigos y yo, los mensajes empiezan a ser un tema recurrente de conversación, una suerte de expectativa. “¿Qué te pone hoy?", me dicen “¿Qué te pone?” También ellos se sorprenden.

"Escribir contigo", respondo. Entonces, sonríen. Hacen apuestas, cruces, posibilidades. Cada día ellos preguntan, y yo contesto.

Dice: “Tú, aquí, ahora."

Dice: "Solo a ti."

Dice: "Sentir-te."

Dice: "Empápate de locura."

Y entonces lo hago. Lo leo y lo hago, me embadurno por entero.

Ahora, mis amistades creen que debo de madrugar más y esperar en la playa. Le llaman "poeta de la arena". Pero no, no quiero. No deseo que se acabe. Me gusta así. Me da igual quién escriba, me da igual a quién le escriba, es a mí a quien dice, en cada texto. Yo lo siento así. Y no quiero más. 


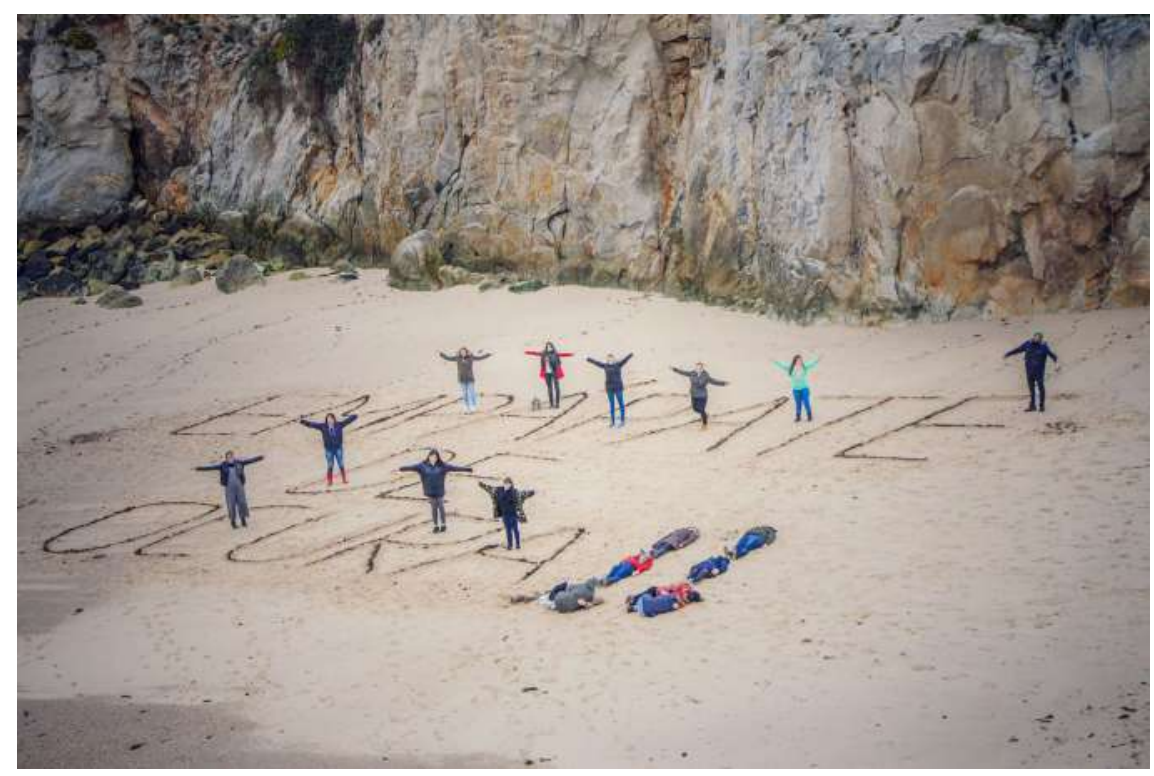

Figura 5. Empápate de Locura. CIFP Ánxel Casal (marzo de 2017). Foto de David Varela Ramos y Vita Martínez Vérez.

\section{ANÁLISIS DE LOS RELATOS}

A continuación, en este apartado próximo a la "discusión científica", se comparan las distintas narraciones ofrecidas por los protagonistas, atendiendo a las cuatro dimensiones mencionadas en el análisis de la propuesta pedagógica. En ellas se observa cómo la comunicación es hija de dos procesos: el habla que dice y el silencio que escucha e interpreta, transformando la voz en alteridad (Gueyrand, 2015). Los procesos comunicativos se caracterizan por ser actos significativos, en la necesidad que tienen de ser comprendidos (Segura-Cabañero y Simó-Mulet, 2017); simbólicos, en cuanto son fruto de un flujo interpretativo (López Fernández y Gauli, 2000); y emocionales, en tanto con-mueven a aquellos que los escuchan (Sánchez-Ruiz, Chacón y Belda, 2011). Los tres relatos anteriormente construidos reflejan estos tres rasgos, aunque en cada uno de ellos un aspecto se impone sobre los otros dos, de tal manera que podemos decir que la narración se construye en torno a este. 
La voz del mensaje que busca interlocutor pretende ser oída y reconocida en esos otros que buscan sentirse interpelados por "la rutina de lo inesperado". Detrás de cada letra existe una mujer-arena que narra la voz del océano, en una suerte de diálogo escrito sin más respuesta que la espera. Así, con tesón administrativo, desentierra las palabras y cava su voz en la resonancia de la ciudad (Macaya, 2017).

El rasgo más significativo de la voz que escribe este primer relato es la intencionalidad de expresar la interioridad de las personas, sin otra finalidad que el deseo de ser escuchada y replicada por alguien, de ahí la visibilidad de la acción, que busca impactar en la ciudadanía, empleando un espacio público y alterando la función de este.

En la segunda narración, el jardinero necesita entender algo que, para él, resulta del todo inexplicable, "a veces pensaba, hoy no. Hoy no puede ser posible”. En este sentido, la frase más repetida en el relato es “¿Por qué?”, la cual aparece 3 veces, hasta que la proponente le contesta de un modo tautológico que le hace pensar en el sentido de la expresión humana "Entonces dijo: por qué no. Y comprendí". Posteriormente, el saberse dedicado en un mensaje y anhelar la escritura, le hace comprometerse con la acción (Tejo, 2017), adoptando un "papel notarial" ante aquellos que, como él, sientan que el deseo de expresar no es razón de peso para decir, ya que, tal y como dice Ortega (2013), "la pedagogía de la alteridad es una pedagogía mostrativa (del testimonio)" (p. 409).

El tercer relato nace de un acto comunicativo consciente, dirigido a una persona concreta, atendiendo a la enfermedad que duele en la empatía, así, Aloia recibe en el hospital, donde es ingresada para tratarse de la recaída de un tumor, un mensaje personal en formato vídeo que le recuerda el deseo de vivir; a menudo sucede que "La enfermedad nos hace enfrentarnos con la muerte en una sociedad que vive como si esta no fuera a suceder jamás" (López Fernández y Gauli, 2000, p. 56).

La frase dedicada simboliza para ella la enfermedad y el deseo de sanar, "fue tal el impacto de las letras (...), que, una vez superado el desenlace, me tatué el mensaje en el brazo. (...) No me rendiré nunca”. Es evidente que, ante la incerteza, la recepción de un mensaje de esperanza permite a la persona emocionarse, "Lloré de vida", y continuar su proceso de curación, simbolizando en la escritura de su propia piel la decisión asumida. Así pues, este relato muestra que solo es posible edificar la identidad sobre la memoria (Ortega, 2013).

La autora del cuarto relato ve cómo su rutina es sorprendida por una sucesión de mensajes que cobran para ella un significado personal. En este 
caso no se trata de un mensaje expresamente dirigido a ella, aunque lo reciba de este modo. Así, se observa cómo, desde el principio, la protagonista de la narración hace una apropiación emocional del mensaje, narrada en las primeras hipótesis de autoría, deseando formar parte de la creación relacional de ese alguien (López Fernández y Gauli, 2000), ¿Será para mí? ¿Quién lo habrá escrito? ¿Él?; premisa que transmite a sus amistades, quienes, de forma reiterada asumen la certeza de la relación entre escritura y protagonista, y sugieren formas de averiguar la identidad del autor, incluso llegan a proponer "que le deje un comentario, como un post".

Otro aspecto por resaltar de este relato es la prevalencia de construir un significado propio, a medida de sus necesidades, sobre el deseo de revelar la autoría (Macaya, 2017), "pienso en hacerlo, pero no me atrevo. Es mejor así, seguir jugando con el misterio, sintiéndome parte. Prefiero."

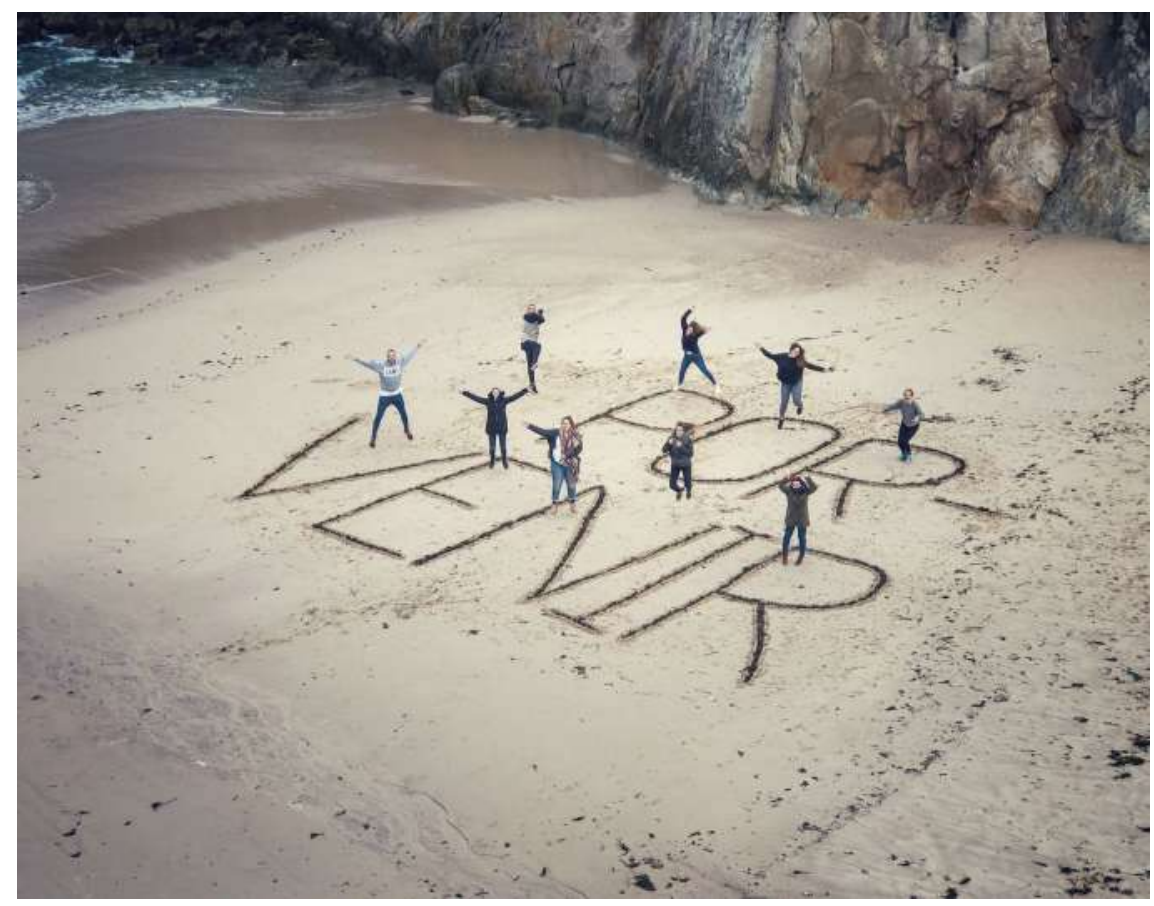

Figura 6. Por-Venir. CIFP Ánxel Casal (marzo de 2017). Foto de David Varela Ramos y Vita Martínez-Vérez. 


\section{CONCLUSIONES}

La interacción de los aspectos comunicativos que conforman los microrelatos da forma a las conclusiones del estudio en cuanto a las dimensiones planteadas en el análisis de la propuesta pedagógica.

1. En relación con la interacción entre la ciudadanía y la acción artística propuesta, se observa que cualquier acto comunicativo implica a la comunidad, en cuanto tiene capacidad de transformar, individualmente y/o colectivamente, el lugar que ocupan las palabras, entre el yo que emite y el otro que recibe e interpreta desde sí. No pasa desapercibido.

2. Atendiendo a la comprensión de la acción, las circunstancias del receptor dan sentido a la comunicación, tanto desde un punto de vista significativo, como simbólico y emotivo; tejiendo de este modo el discurso del emisor, en el tapiz de la propia vida, la cual pasa a ser entendida como la narración conjunta del nos-otros construido.

3. Desde la escena de la vida cotidiana, se puede afirmar que ningún espacio es neutro, en tanto que es susceptible de formar parte de un discurso humano. Así pues, el aula habla del mismo modo que lo hace el paisaje, pero mientras que el primero se crea "para enseñar", el segundo, simplemente, existe y es, permitiendo que sea interpretado.

4. Los aprendizajes transversales vinculados a la vivencia y a la emoción han de concretarse en estrategias educativas globales que se centren en la experiencia conjunta de las acciones, posibilitando a las personas individualizarse en el significado y encontrarse con otros en los significantes.

\section{REFERENCIAS}

Aleixandre, V. (1932). Espadas como labios. Madrid, España: Espasa Calpe.

Bachelard, G. (1982). La poética de la ensoñación. Madrid, España: S.L. Fondo de Cultura Económica de España.

Bauman, Z. (2007). Pensando sociológicamente. Buenos Aires, Argentina: Ediciones Nueva Visión.

De Keulenaer, F. (2008). Panel Survey. En Lavrakas, P. (ed.). Enciclopedy of Survey Research Methods (pp. 570-573). Thounsand Oaks, California, United States: Sage.

Giráldez, A. y Prince, S. (2017). Habilidades para la vida: aprender a ser y aprender a convivir en la escuela. Madrid, España: SM.

Gueyrand, B. (2015). La palabra en el camino. Arteterapia - Papeles de arteterapia y educación artística para la inclusión social, 10, 87-104. 
López Fernández, M. y Gauli, J.C. (2000). El cuerpo imaginado. Revista Complutense de Educación, 11(2), 43-57.

Macaya, A. (2017). Trayectos en el mapa: artes visuales como representación del conocimiento. Arte, Individuo y Sociedad 29(2), 387-404.

Martínez-Vérez, M.V.; Abad-Molina, J.; Hernández-Pinzón, D. (2017). El telar de la desmemoria y la metáfora del bordado. Arte relacional desde una perspectiva intergeneracional y de género. Arte, Individuo y Sociedad, 29(No especial), 223-238.

Moreno, A. (2015). Arte como herramienta social y educativa. Revista Complutense de educación 26(2), 315-329.

Ortega, P. (2013). La pedagogía de la alteridad como paradigma de la educación intercultural. Revista Española de Pedagogía 256, 401-442.

Ruiz Olabuénaga, J.L. (2012). Metodología de la investigación cualitativa. Bilbao, País Vasco, España: Universidad de Deusto.

Sánchez-Ruiz, J.; Chacón, P.; Belda, N. (2011). La lógica poética. Una fenomenología del pensamiento artístico. Arte, Individuo y Sociedad 23(1), 9-18.

Segura-Cabañero, J; Simó-Mulet, T. (2017). Espacialidades desbordadas. Arte, Individuo y Sociedad 29(2), 219-234.

Sun Woong, K. (2008). Panel. En Lavrakas, P. (ed.) Enciclopedy of Survey Research Methods (pp.564-566). Thounsand Oaks, California, United States: Sage.

Tejo, C. (2017). Proyectos de arte de acción: análisis de una experiencia pedagógica. Arte, Individuo y Sociedad 29(2), 203-217.

Terrones, A. (2013). Usar en caso de performance. Estudio del proceso creativo en el arte de acción. Efímera 4(5), 32-41.

Vidal Jiménez, R. (2006). Discursos feministas y condición postmoderna. Revista de investigaciones políticas y sociológicas 5(1), 25-38.

Watzlawich, P., Beavin, J. y Jackson, D. (2002). Teoría de la comunicación humana. Barcelona, España: Herder.

Winnicott, D.W. (1971). Realidad y juego. Barcelona, España: Gedisa.

Zaliasnik, Y. (2017). Villa o cómo practicar (y abrir o ampliar) un lugar y sus memorias a través de la teatralidad, Alpha 44, 221-222.

Zaragoza, J.; Luis-Pascual, J.C. y Manrique, J.C. (2009). Experiencias de innovación en docencia universitaria: resultados de la aplicación de sistemas de evaluación formativa Red U. Revista de Docencia Universitaria 4. Consultado (19/01/2018) en http://www.redu.um.es/red_U/4/ 